\title{
Nilson Lage: uma teoria do jornalismo a partir da prática
}

\section{Karina Woehl de Farias ${ }^{1}$}

\section{Resumo}

Este trabalho tem como objetivo reportar a contribuição da obra do professor e pesquisador brasileiro Nilson Lage para uma Teoria do Jornalismo. O texto apresenta conceitos construídos por Lage em seus seis livros, com ênfase no Ideologia e Técnica da Notícia (1979), sua mais consagrada obra no campo dos Estudos em Jornalismo. Questões históricas e ideológicas sobre a imprensa, além da organização e hierarquia da informação estão entre as questões analisadas. A pesquisa utilizou revisão bibliográfica e entrevista não estruturada com o autor como metodologia.

Palavras-chave: Jornalismo. Nilson Lage 2. Notícia 3.

\section{Abstract}

This paper aims to report the contribution of the work of Brazilian professor and researcher Nilson Lage to a Theory of Journalism. The text presents concepts constructed by Lage in his six books, with emphasis on Ideologia e Técnica da Notícia (1979), his most consecrated work in the field of Journalism Studies. Historical and ideological aspects of the press, besides the organization and the hierarchy of information, are among the issues analyzed. The research used bibliographical review and unstructured interview with the author as methodology.

Keywords: Journalism; Nilson Lage; News.

\section{Introdução}

Um personagem importante do jornalismo brasileiro, Nilson Lage marcou gerações de acadêmicos e jornalistas Brasil afora. Seus livros são bibliografia básica nas faculdades e universidades de comunicação há décadas, ratificando seu pioneirismo nos estudos teóricos, principalmente, sobre a notícia. Junto com nomes importantes da área

\footnotetext{
${ }^{1}$ Doutoranda do Programa de Pós-Graduação em Jornalismo da Universidade Federal de Santa Catarina (UFSC), Mestra em Educação pela Universidade do Extremo Sul Catarinense (UNESC) e professora do curso de Jornalismo da Faculdade Satc, em Criciúma-SC. Integrante do Grupo de Investigação em Rádio, Fonografia e Áudio (Girafa), certificado no CNPq. E-mail: karina.farias@satc.edu.br

Revista Pauta Geral-Estudos em Jornalismo, Ponta Grossa v.5, n.2, p.75-88, Jul/Dez 2018.
} 
no país, integra a lista de pesquisadores que impulsionaram o desenvolvimento de uma Teoria do Jornalismo, que nasce segundo Lage $(2018)^{2}$, a partir de sua prática.

Professor de opiniões fortes e contundentes, Nilson Lage iniciou na carreira profissional de jornalista por acaso. Estudante de Medicina por pouco mais de três anos, precisou largar os estudos médicos para auxiliar a família, que perdera o pai muito cedo. É então que seu contato com os meios de comunicação acontece. Seu primeiro emprego se dá em um jornal, onde inicia sua trajetória que mais tarde o leva para o mundo acadêmico para pesquisar e lecionar.

Formado em Letras, com mestrado em Comunicação e doutorado em Linguística pela UFRJ, seus conceitos sobre notícia mesclam sua prática com os estudos teóricos sobre linguagem. Trabalhou em redações consagradas como o Jornal do Brasil, O Globo, Última Hora, Revista Manchete e na Televisão Educativa. Na década de 1990, incentivado por professores da UFSC, presta um novo concurso na universidade catarinense, onde auxilia na implantação do curso de pós-graduação e leciona até se aposentar, aos 70 anos, de forma compulsória. Antes disso já havia se aposentado na UFRJ e na UFF, onde ajudou a formar gerações de jornalistas cariocas, e já era um jornalista e professor consagrado nacionalmente antes mesmo de publicar seu primeiro livro. Hoje reside em Santa Catarina, estado que o acolheu como o grande pesquisador que sempre foi. "Minha relação com a UFSC se deu porque o Adelmo Genro Filho citou em seu O Segredo da Pirâmide amplamente o meu livro, então me chamavam muito para palestras até que começaram a pedir para eu vir para cá, prestei concurso e fiquei" (LAGE, 2018).

Conforme o próprio autor, seu acervo de conhecimento começou ainda nos tempos de adolescente, quando Nilson Lage estudou em colégio militar. Ele mesmo aponta sua qualidade na escrita ao rigor do ensino recebido na capital carioca. Leitor assíduo desde adolescente, "bebeu de fontes" como Ivan Pavlov e Sigmund Freud para se aprofundar no comportamento humano, mesmo sendo crítico dos estudos do segundo autor. A literatura com viés político marxista também sempre esteve presente em sua vida, como John Hohenberg, Mikhail Bakthin e György Lukács. Na linguagem, orgulha-se de ter lido todas as obras de Roland Barthes e, mais recentemente, tem referenciado Teun Van Dick.

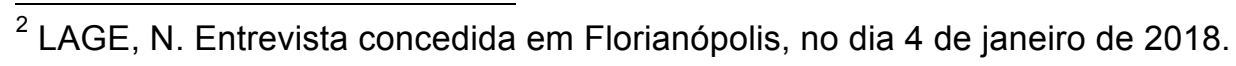

Revista Pauta Geral-Estudos em Jornalismo, Ponta Grossa v.5, n.2, p.75-88, Jul/Dez 2018. 
Autor de seis obras consagradas no meio acadêmico, Lage atualmente se dedica a escrever textos sobre linguagem, sem pretensão de publicá-los, bem como é atuante nas redes sociais com posicionamentos fortes sobre a política, a economia e a cobertura da mídia como um todo. Seu perfil no Facebook é atualizado diariamente com comentários e compartilhamentos de notícias. Tem se dedicado à criação de um site pessoal chamado Observador do Mundo, onde publica seus livros, textos, artigos e algumas memórias. Em 2017, um grupo de pesquisadores da UFSC, entre eles os professores Eduardo Meditsch, Samuel Lima, Lara Lima e o cinegrafista Henrique Guião, iniciou as gravações de um documentário sobre a vida e a obra de Nilson Lage. A iniciativa faz parte de um projeto de extensão do curso de Jornalismo da Universidade Federal de Santa Catarina e está na dependência de financiamento e recursos para ter continuidade. A intenção é coletar imagens e entrevistas com o autor também no Rio de Janeiro, cidade onde nasceu e começou sua vida acadêmica.

Os seis livros de Nilson Lage influenciaram o pensar sobre jornalismo no Brasil. Os títulos do autor são: Ideologia e Técnica da Notícia (1979); Estrutura da Notícia (1987); Linguagem Jornalística (1987); Controle de Opinião Pública (1998); A Reportagem: teoria e técnica da pesquisa jornalística (2001) e Teoria e Técnica do Texto Jornalístico (2005). O primeiro deles se tornou um marco em sua trajetória de pesquisador e já está em sua quarta edição. A Linguagem Jornalística e a Estrutura da Notícia, são livros que derivam da sua primeira obra, originalmente sua dissertação de mestrado na UFRJ. O primeiro "defende uma linguagem propriamente jornalística, na interseção entre os registros coloquial e formal e sujeita à necessidade de comunicar e aos compromissos ideológicos do uso da linguagem, como os processos de resistência, nomeação, eufemismos e relexicalizações" (AZEVEDO, 2013). O segundo aponta a hierarquia da notícia por meio de princípios de seleção, ordenação e nomeação, "segundo uma lógica que estrutura o texto a partir de aspectos mais importantes e interessantes, distribuídos em elementos básicos como o lide, em suas diversas tipologias" (AZEVEDO, 2013).

Em A reportagem: teoria e técnica de entrevista e pesquisa jornalística, o professor faz uma espécie de manual com dicas e macetes utilizados por muitos acadêmicos e docentes. Já em Teoria e Técnica do Texto Jornalístico, a estrutura e o estilo do texto jornalístico são tratados de forma mais reflexiva, como apresenta Azevedo (2013), afirmando que o livro parte da lógica formal ancorando as reflexões do autor na pragmática conversacional.

Revista Pauta Geral-Estudos em Jornalismo, Ponta Grossa v.5, n.2, p.75-88, Jul/Dez 2018. 
Lage sinaliza em seu currículo Lattes duas obras como mais relevantes de sua carreira: Ideologia e Técnica da Notícia e Controle de Opinião Pública. Em entrevista à autora deste artigo em janeiro de 2018, ele foi categórico, declarando que o segundo foi o de maior amadurecimento acadêmico. "A minha dissertação eu fiz durante as disciplinas, trabalhava muito e fazia o curso. O outro foi com mais fôlego, reflete a experiência que eu tive de perceber como os mecanismos de opinião pública foram mudando" (LAGE, 2018). A ideia central de Ideologia e Técnica da Notícia, livro que propõe uma teoria da notícia, será ampliada neste trabalho que objetiva traçar um perfil da contribuição de Nilson Lage para os Estudos em Jornalismo.

\section{Uma Teoria da Notícia}

O ano era 1979, dois anos após a apresentação de sua dissertação na Universidade Federal do Rio de Janeiro. Ideologia e Técnica da Notícia "caiu no gosto" dos leitores virando uma referência obrigatória nos cursos de Jornalismo mais por acaso do que intencionalmente, assim como a própria trajetória de seu autor. "Na verdade, a vida que leva a gente, não é a gente que leva a vida" (LAGE, 2018).

A publicação de sua mais marcante obra ocorreu porque um conhecido trabalhava em uma editora e resolveu colocá-la em circulação sem que Nilson soubesse. Em seguida, os exemplares se esgotaram e, atualmente, o livro que o consagrou como um dos nomes atuantes da pesquisa em jornalismo no Brasil está em sua quarta edição, revisada e atualizada em relação às rotinas, e ao jornalismo produzido na internet. No entanto, as referências usadas pelo autor continuam originais e remetem à década de 1970, o que não altera o fato do livro seguir sendo uma obra canônica para área jornalística.

Nilson Lage está entre os autores nacionais com maior número de citações em teses e dissertações do Programa de Pós-graduação em Jornalismo da Universidade Federal de Santa Catarina, curso que ajudou a fundar. Entre os brasileiros, ele fica atrás, por apenas um trabalho de diferença, para o professor e amigo Eduardo Meditsch. Ambos foram citados em quase uma centena de pesquisas nos dez anos de atuação do POSJOR (MEDITSCH; AYRES; BETTI, 2017, p.12). Muitas destas referências se deram por meio de Ideologia e Técnica da Notícia.

O livro se baseia em questões históricas e ideológicas sobre a imprensa. Na parte inicial, Lage resgata pontos interessantes sobre o início do jornal como meio de controle Revista Pauta Geral-Estudos em Jornalismo, Ponta Grossa v.5, n.2, p.75-88, Jul/Dez 2018. 
social. "Por detrás da evolução da Imprensa, do surgimento dos periódicos, de suas formas, conteúdos e técnicas de produção, encontra-se o processo de surgimento e afirmação da burguesia" (LAGE, 2012, p.21). A presença da força do capital na produção da notícia é sempre muito constante nos textos e falas do jornalista, como ao afirmar que o nascimento da própria imprensa rompeu o monopólio entre Estado e Igreja, criando assim condições de impulsionar o texto jornalístico como ferramenta de propaganda e informação. A liberdade de expressão abarcada pelo pensamento burguês levou o jornal a cargo de um instrumento de luta ideológica, como jamais deixaria de ser. "A liberdade, hoje sabemos, é do capital. E a verdade impressa lhe pertence" (p.44). Fato reforçado em Adelmo Genro Filho (2012, p. 91-92) ao afirmar dentre as especificidades do jornalismo que "nada ficamos sabendo, exceto aquilo que é patrimônio universal: o jornalismo com o desenvolvimento das relações capitalistas, no bojo, na cultura de massa, e expressa, hegemonicamente, uma ideologia que visa ao controle e a eterna reprodução da sociedade burguesa". José Marques de Melo (2006, p.57), contemporâneo de Nilson Lage, também fala a respeito, mesmo que de forma mais sútil, sobre a ideologia no jornalismo.

\begin{abstract}
Esse traço do jornalismo, no alvorecer da sociedade burguesa vai se esmaecendo na medida em que a própria burguesia, como classe dominante, cria artifícios para descaracterizar o processo de dominação social e instaurar no senso comum a ideia de uma sociedade em que os conflitos de classe não existem. [...] e, com isso, ocorre um processo sutil de "desideologização", despolitização do jornalismo. Emergem os conceitos de objetividade, neutralidade, imparcialidade, que, na verdade, são os pilares da própria "ideologia do jornalismo" na sociedade capitalista.
\end{abstract}

Já ao mencionar o aparecimento do jornal enquanto empresa, Nilson Lage aponta a criação da tríade que sustenta os veículos até os dias de hoje: quem produz quer interesse do público que irá retribuir consumindo produtos (industriais, de serviços ou ideológicos). "As grandes e pequenas questões da ideologia estão presentes na linguagem jornalística, porque não se faz jornalismo fora da sociedade e do tempo histórico" (LAGE, 1985, p.42).

Em seguida, a obra traz para ao debate questões como os conflitos ideológicos que trouxeram para as práticas jornalísticas princípios como a imparcialidade e a objetividade. Lage é um dos autores que rompem com o conceito da necessidade, quase que imperativa, de uma objetividade jornalística. Criada nos Estados Unidos num Revista Pauta Geral-Estudos em Jornalismo, Ponta Grossa v.5, n.2, p.75-88, Jul/Dez 2018. 
momento de revolução no "fazer jornalismo", ela surge como mais um mecanismo de defesa profissional e moeda de troca da indústria da notícia, se consolidando nas décadas de 1920 e 1930, após a Primeira Guerra Mundial.

Segundo Schudson (2010), essa objetividade aparece como um conjunto de regras que acaba por substituir a crença nos fatos por confiança na informação, indo de encontro a um determinismo tecnológico daquela época. Para o autor (2010, p. 144), é neste momento consensual de separação entre fatos e valores, que a objetividade se estabeleceu, surgindo "não tanto como uma extensão do empirismo ingênuo e da crença nos fatos, mas como uma reação contra o ceticismo; não se tratava de uma extrapolação linear, mas de uma resposta dialética à cultura da sociedade democrática de mercado".

Lage refuta este modelo fechado, declarando que a forma como essa objetividade foi imposta prejudicou uma construção e transformação de conhecimento. Talvez resida aí uma de suas maiores contribuições para uma Teoria do Jornalismo.

Um jornalismo que fosse a um só tempo objetivo, imparcial e verdadeiro excluiria toda outra forma de conhecimento, criando o objeto mitológico da sabedoria absoluta. [...] O conceito de objetividade posto em voga consiste basicamente em descrever os fatos tal como aparecem: é, na realidade, abandono consciente das interpretações, ou do diálogo com a realidade, para extrair desta apenas o que se evidencia (LAGE, 2012, p. 31 e 32).

Porém, mesmo criticando esta ausência de reflexão diante desta objetividade idealizada, o autor também encontra vantagens conquistadas na prática jornalística. Um exemplo disso, ele lembra, foi o compromisso com a realidade material, a aceleração na apuração e a redução na manipulação da informação, consequências diretas da aplicabilidade da objetividade no texto jornalístico. "A objetividade, em jornalismo, é meta que se traduz numa série de técnicas de apuração, redação e edição; na busca de enunciados intimamente adequados à realidade e em sua tradução para diferentes públicos e veículos" (LAGE, 2006, p. 49).

Entretanto, mesmo propondo uma Teoria para Notícia, baseada na "transmissão da experiência - isto é, na articulação simbólica que transporta a consciência do fato a quem não a presenciou", (Lage, 2012, p. 45), o autor e outros pesquisadores de sua geração são, não raras vezes, criticados pelo reducionismo de suas obras, apontadas como grandes manuais e com pouco fôlego teórico. No entanto, a contribuição das obras técnicas foram fundamentais para os estudos da área, como aponta Jorge Pedro Sousa 2018. 
(2013, p. 83) ao descrever que "os manuais de jornalismo tornaram-se comuns entre o final do século XIX e os princípios do século XX, devido ao afluxo de neófitos à profissão e à generalização dos cursos de jornalismo. Esses manuais, a seu modo, contribuíram para a teorização do jornalismo a partir do século XIX".

Lage (2018) concorda que muitos livros foram originados de manuais, mas emenda, afirmando que "os manuais são a base e a produção da relação concreta com a realidade. Porque se você sai dessa relação, você deixa de fazer jornalismo e passa a fazer sociologia". Além disso, em Ideologia e Técnica da Notícia, ele também ressalta que a técnica de fazer jornal não é a mesma coisa que a tecnologia de fazer jornais, ou seja, por meio de uma prática surge uma teoria.

O conceito que eu tenho sobre jornalismo é que jornalismo é uma prática, como tudo é prática; medicina é prática, engenharia é prática. Antes das faculdades de engenharia já existiam as pirâmides do Egito, ou seja, antes e mais nada, práticas, sobre as quais se aplicam conhecimentos científicos. Na medicina se aplicam a biologia, a química, a psicologia. No jornalismo, a mesma coisa, são aplicados uma série de conhecimentos, linguísticos, sociais, de informática. Agora, como em toda prática é possível construir, a partir dela, uma teoria. E isso é sempre algo em construção, qualquer teoria que você faça sobre uma prática, é uma teoria. Em suma, toda prática humana gera uma teoria. No caso do jornalismo, toda maneira moderna das civilizações lidarem com a realidade passa por uma estrutura de conhecimento" (LAGE, 2018).

Apostando nisso, Nilson Lage entende que o jornalismo não é só a notícia, mas a forma mais canônica do jornalismo seria a notícia. Sendo assim, uma Teoria da Notícia pode ser considerada parte desta Teoria do Jornalismo. Este é um dos pontos centrais do principal livro de Nilson Lage (2012, p.50), apontando filtros técnicos e ideológicos, a partir do momento que entende a notícia como o "relato de uma série de fatos a partir do fato mais importante, e este, de seu aspecto mais importante". Para o autor, o "importante" se aproxima dos conceitos de verdade e interesse humano, ou seja, estes filtros separam a informação de crenças individuais.

Poucos anos depois, Adelmo Genro Filho (2012, p. 141), reconhece a contribuição de Lage ao referenciá-lo em sua obra. "Nilson Lage, portanto, dá um passo à frente em relação à mentalidade artesanal que, via de regra, está por trás das críticas ao 'jornalismo burguês' e ao 'mito da objetividade'". Entretanto, o autor de O Segredo da Pirâmide, também não deixou de criticar o colega, quando diz que ele deixa um vácuo teórico entre a objetividade e a imparcialidade do jornalismo. Para Adelmo (2012, p. 143), a análise do Revista Pauta Geral-Estudos em Jornalismo, Ponta Grossa v.5, n.2, p.75-88, Jul/Dez 2018. 
autor sobre o jornalismo fica estanque em "aspectos linguísticos e lógicos do fenômeno", mas reconhece o fôlego de Lage ao descrevê-lo como uma espécie de simulação da imediaticidade.

No decorrer do livro Ideologia e Técnica da Notícia, a definição de lide, reportagem e hierarquia da notícia também se fazem presente. Ao descrever a notícia diante dos critérios de nomeação/seleção/ordenação, Lage acentua a subjetividade do jornalista (ideologia) e o caráter de livre escolha deste profissional. Além disso, elenca a partir deste trinômio, os valores-notícia, definidos por critérios pessoais do editor, bem como os tensionamentos das rotinas produtivas e das atitudes profissionais. Os critérios de noticiabilidade destacados são: proximidade; atualidade, identificação social; intensidade; ineditismo e identificação humana.

Em relação à reportagem, o professor (2012, p. 47) diferencia os gêneros pontuando que "a notícia distingue-se com certo grau de sutileza da reportagem, que trata de assuntos, não necessariamente de fatos novos. A reportagem é planejada e obedece uma linha editorial, um enfoque; a notícia não". Já sobre o lide brasileiro, Lage o codifica em "sequências de tópicos frasais seguidas por documentações realizadas de formas descritiva, narrativa ou de acordo com transcrições textuais" (AZEVEDO, 2013).

A parte final do livro faz um diálogo entre verdade e as notícias. Primeiramente, Lage discute a verdade na ciência, a verdade histórica e fecha falando da informação jornalística. Para ele, as notícias são relatos de aparências que "escondem" relações de poder. "E vemos ainda aí, a apropriação interessada de conhecimentos particulares a serviço de interesses globais; de umas verdades por outra verdade, do poder que alimenta assim a ideologia" (LAGE, 2012, p.133).

Para o campo, a dissertação de mestrado de Nilson Lage rendeu inúmeras citações e pode-se dizer que o colocou no seleto grupo de clássicos do jornalismo. Seus estudos mudaram a forma que a universidade enxergava a área, sempre atrelada à comunicação. Mas é importante citar que para o autor, seu livro de maior peso teórico não foi Ideologia e Técnica da Notícia, mas sim Controle de Opinião Pública - uma verdade conveniente que, em seu entendimento, foi feito em um momento de maior amadurecimento acadêmico.

O livro, publicado em 1998, foi fruto de projeto de pesquisa enquanto lecionava na Universidade Federal de Santa Catarina. Dividido em 14 densos capítulos, a obra parte da linguagem, que implica convencimento, e da lógica que delimita a falácia (LAGE, 1998). Revista Pauta Geral-Estudos em Jornalismo, Ponta Grossa v.5, n.2, p.75-88, Jul/Dez 2018. 
Ele perpassa por questões históricas de como funcionam as sociedades, a lógica e o pensar humano. O livro, com reflexões profundas, traz cenários factuais da época e por isso, ao ler, é preciso de conhecimentos prévios para o entendimento, principalmente, da segunda metade da obra. Mas mesmo passando-se duas décadas, seus textos parecem atualizados e em sintonia com a realidade atual, quando aponta a "contaminação" das ciências humanas por uma hierarquia de valores que vai de encontro com uma reflexão sobre a realidade, bem como sobre a pluralidade do discurso social nos meios de comunicação.

A nítida impressão que se tem passando pelos canais de uma rede de tevê por cabo ou pela mesmice das rádios FM é que nada se tem a dizer ou mostrar. A avaliação do que é notícia também se padroniza de maneira conveniente: por exemplo, qualquer greve que não tenha desdobramentos violentos ou manifestações circenses deixou de ser notícia (LAGE, 1998, p. 397).

A afirmação datada na década de 1990 parece atemporal, avaliando-se o cenário atual do jornalismo produzido no Brasil. O tema será ampliado na sequência em entrevista realizada com o próprio autor com objetivo de entender se as percepções do pesquisador sobre a área seguem as mesmas ou mudaram com o passar dos anos.

\section{O pensamento de Lage na atualidade}

Mesmo se passando quase quatro décadas desde que publicou Ideologia e Técnica da Notícia, quando Nilson Lage começa a teorizar sobre a prática profissional, o conceito do autor sobre o que chamou de forma mais canônica do jornalismo, a notícia, é mantido na atualidade. O pensamento de um dos grandes pensadores contemporâneos do jornalismo foi um dos temas tratados em entrevista presencial realizada em janeiro de 2018, em Florianópolis, na residência de Lage, para complementar este artigo.

Conforme Lage (2018), o princípio básico da notícia continua sendo o que interessa, "qual o aspecto da realidade é o mais interessante, e hierarquizar os fatos é uma peculiaridade do jornalismo, o que a ciência não consegue fazer". Fazendo críticas duras ao momento atual da mídia brasileira, o autor afirmou durante a conversa que, ao longo dos anos, viu uma verdadeira deformação do jornalismo enquanto profissão.

Continuo achando que é possível relatar o que se passa no mundo honestamente, com o viés possível da cultura, da classe, mas com uma narração objetiva, voltada para o objeto, não para o fim. Eu posso contar um atropelamento com base nele, não no efeito na pessoa que vai ler. $A$ objetividade para mim é o que a informática diz, é um discurso voltado 
para o objeto. Os demais conceitos são políticos. [...] Sempre se investiu para dominar as pessoas, como os mecanismos de controle de opinião pública, todo conhecimento foi voltado para isso. Essa influência deformou o jornalismo. Por que, se você tenta fazer um discurso voltado para realidade dizem que você é parcial? Por que eu não posso ser honesto? Por que eu tenho que ser instrumento de alguém? Por que eu não posso ver honestamente a partir do que eu sou e o que o mundo é? No lugar de tirar a realidade, o meu horizonte, eu tenho que ter um horizonte prévio da realidade? Por que eu tenho que ter uma sabedoria antes do fato? A sabedoria está no fato e não fora dele. Temos que tirar a teoria da nossa experiência. Quando não se tem essa visão, essas deformações ocorrem (LAGE, 2018).

Com a afirmação, Nilson Lage deixa claro o seu posicionamento diante da objetividade e da produção de conhecimento por meio da leitura que o Jornalismo faz da realidade. Para o pesquisador (2018), o jornalismo é conhecimento da própria realidade, envolvendo interpretações e análises. "A informação é sempre um reprocessamento. Cada pessoa que vê um fato constrói diante daquele fato, com relação ao seu conhecimento, uma informação diferente. Um mesmo fato gera vários tipos de informação, isso permite mil possibilidades de se tratar um fato honestamente". Conforme o pesquisador, uma teoria do jornalismo está diretamente vinculada à Ciência da Linguagem, numa lógica que perpasse a sintaxe e a semântica, semiologia e Teoria do Conhecimento. "Como linguagem, o jornalismo transita entre a condição social e a psicologia dos indivíduos" (LAGE, 2018).

A resposta de Lage coaduna com o pensamento de Adelmo Genro Filho (2012, p. 216) quando ressalta que o jornalismo "é a cristalização de uma nova modalidade e percepção e conhecimento social da realidade através de sua reprodução pelo ângulo da singularidade". Nessa reprodução, segundo Genro Filho (2012), encontra-se uma base histórica objetiva e subjetiva repleta de relações, como também pontuou Nilson Lage, ou seja, o jornalismo como forma de conhecimento também é construído por meio de questões relacionais, onde as apropriações particulares do conhecimento singular são distintas da maneira como a ciência aborda o mundo.

É uma forma social do conhecimento sim, mas não se esgota aí, você vai tendo mais relações e criando informações mais sofisticadas, construindo. Quanto mais experiência o sujeito tem, melhor ele vai relatar, ou seja, um jornalista para produzir análise de fatos deveria ter uma experiência que hoje ele não tem. Quando a gente conta uma história a outro, você começa por aquilo que entende de mais importante. 
Essa relação de você construir algo do que você acha interessante, não está em teoria nenhuma (LAGE, 2018).

Assim, a consolidação do jornalismo e de uma teoria sobre ele, segundo Nilson Lage, passaria também pelo fortalecimento da categoria e do ensino no país. Durante a entrevista, o professor afirmou que a qualidade dos cursos superiores na área é muito fraca, o que dificulta a formação de bons profissionais. Nilson Lage ainda lembrou da organização dos cursos de comunicação na década de 70. Segundo ele (2018), o modelo de currículo foi uma imposição da CIA (Central Intelligence Agency) por meio de um projeto estruturalista. "Foi uma imposição com um projeto teórico absurdo, juntando profissões ao acaso, por exemplo, tem Jornalismo, mas não tinha Ensaísta. Tinha curso de Cinema, mas não tinha Teatro, Artes Visuais, mas não tinha Design. Essas incoerências de dominação". Na avaliação do autor, o problema na formação já inicia no ensino médio, onde o aluno muitas vezes sai sem saber escrever corretamente.

Primeiro um jornalista tem que saber escrever, tem que ter um texto perfeito. Segundo ele tem que dominar os instrumentos técnicos da profissão e, em cima disso, ter uma cultura. Os laboratórios existem para produzir técnicas, experimentar práticas e estratégias, gerar conhecimento, não para simples reprodução. É a partir da vivência do ofício que se constrói a Teoria do Jornalismo, de onde a prática não se basta como finalidade no ambiente universitário. Teoria e prática não se contradizem, como querem fazer crer: integram-se e se completam em uma relação acadêmica sadia (LAGE, 2018).

Durante a entrevista à autora deste trabalho, Lage (2018) ainda se mostrou descontente com procedimentos burocráticos exigidos na academia e afirmou que a vaidade de muitos pesquisadores "vai destruindo a própria autocrítica, gerando uma entropia na formação do indivíduo", o que afeta o ensino da área. Também criticou o momento atual da sociedade pós-moderna, declarando que vivemos tempos difíceis por disputa de impérios, poder e também de violência.

O controle de opinião pública é uma verdadeira estrutura militar. Ela agride a consciência das pessoas, ela corrompe as pessoas pelo consumo, você constrói substitutos da felicidade e do prazer, você cria um mundo de castrados que se gratificam com simulacros, isso é uma violência. Vivemos hoje um momento onde se estabelece uma lógica do individualismo competitivo, que é verdadeiramente uma lógica sem sentido. [...]inclusive, a indústria do espetáculo é feita para isso, produções feitas para não se pensar ou só estimular sensorialmente, sem sublimar nada. Isso cria uma mentalidade burguesa (LAGE, 2018). 
O autor falou que em tempos de fakenews, fruto desta pós-modernidade, o jornalismo encontra ainda mais obstáculos para o seu pleno exercício, contribuindo para sua deformação. "A realidade ficou tão evidente que ela não pode ser contada, ou você passa a ter um discurso ficcional. Nesse discurso a gente está em plena recuperação econômica, as universidades estão em pleno funcionamento, quer dizer, ficção, 'fajuto', um absurdo". Ele ainda emendou, dizendo que as notícias falsas governam o mundo e, atualmente, as pessoas se acomodaram a achar que elas possam ser verdade. "Polarizados pela luta de classes e condicionados por tradições culturais, os indivíduos agem platonicamente: não acreditam que haja uma realidade externa a eles e que, se houver, seja possível mostrá-la tal como ela é" (LAGE, 2018). Segundo ele, resistir a este modelo é pensar em meios discordantes, sejam eles em publicações marginais, nos meios universitários, em blogs e publicações alternativas. "A internet permite a cada um dizer de público o que pensa, mas não que muitos o ouçam; a soma de muitas vozes é apenas vozerio" (DE OLIVEIRA e JUNIOR, 2016, p. 450).

Por mais que o fazer jornalismo esteja em transformação, como afirmou Nilson Lage, ele ainda parte da representação dos fatos, e para ser jornalismo não pode, nem deve, perder este viés.

\section{Considerações finais}

A construção de teorias que expliquem, ou ao menos tentam explicar, o jornalismo como área capaz de construir conhecimento superou paradigmas que tratavam os meios de forma estanque e/ou isolados. Nilson Lage com sua Teoria da Notícia contribuiu para o desenvolvimento deste processo e da forma como a universidade passou a ver o jornalismo com a devida importância que tem na sociedade. Entender, por meio de suas pesquisas sobre o jornalismo, faz com que possamos perceber o seu real papel de mediador da realidade a fim de criar sentidos e produzir saberes.

O que teóricos como Nilson Lage fizeram pelo campo foi romper paradigmas e defender um jornalismo para além de sua prática, para além de ideologias. As obras do autor foram escritas há décadas, mas o arcabouço teórico deixado pelo professor ecoa até hoje nas universidades do Brasil, tamanha a importância para o campo jornalístico com presença obrigatória nas bibliotecas especializadas na área de comunicação. Se voltado para a prática e com um enfoque um tanto ligado à linguística como apontam alguns críticos de seus livros, sua Teoria da Notícia encabeça a lista de livros mais citados Revista Pauta Geral-Estudos em Jornalismo, Ponta Grossa v.5, n.2, p.75-88, Jul/Dez 2018. 
em trabalhos acadêmicos da área, demonstrando o caráter didático que suas obras representam para estudantes e professores de jornalismo. É evidente que por ser uma teoria e estar em transformação constante, o pensamento de Lage necessitaria de atualização, principalmente em relação às novas mídias e a sociedade atual. Porém, não diminui em nada o peso de sua Teoria da Notícia, afinal é neste processo de contradições que o conhecimento vai se construindo.

Este texto buscou compreender não só a história e a vida do professor e pesquisador Nilson Lemos Lage, mas apresentar e discutir as implicações de seus trabalhos para o jornalismo. Buscou-se salientar a contribuição de Ideologia e Técnica da Notícia por entendermos ser sua obra de maior contribuição para o meio acadêmico. Além disso, este artigo também levantou questões sobre o pensamento atual do autor, principalmente em relação a sua visão de um jornalismo como forma social de conhecimento, abrindo assim uma significação para além de sua ideologia.

Não há como negar a importância de Nilson Lage para os estudos do jornalismo. No entanto, já se faz necessário um reconhecimento maior de seu nome para a área da comunicação como um todo, talvez levar o nome de um prêmio ou outras justas homenagens coroariam o trabalho de mais de cinco décadas de um dos nomes mais marcantes do jornalismo brasileiro. O documentário em andamento, como citado neste trabalho, preenche parte desta lacuna, mas mesmo assim, fica a vontade de tornar seus referenciais marcos em uma área que se fortalece no campo teórico e enriquece o jornalismo. Que isso ocorra ainda em vida e em sua presença.

\section{Referências}

AZEVEDO, N.R. Nilson Lage: valores-notícia sob filtros técnico-ideológicos, 2013. Disponível em: https://nucleojor.wordpress.com/2013/11/28/nilson-lage-valores-noticiasob-filtros-tecnico-ideologicos/. Acesso em janeiro de 2018.

DE OLIVEIRA, D.B.; JUNIOR, F.G.R.. Por uma história comparada do jornalismo testemunhal entre 1964 e 2016: O olhar de Nilson Lage sobre a História, a Comunicação e a Formação. Revista Observatório, v. 2, n. 2, p. 447-469, 2016. Disponível em https://sistemas.uft.edu.br/periodicos/index.php/observatorio/article/view/2125/8723.

GENRO FILHO, A. O Segredo da Pirâmide: para uma teoria marxista do jornalismo. Florianópolis: Insular, 2012. 
LAGE, N. Entrevista concedida a Karina Woehl de Farias. Florianópolis, 4 de janeiro de 2018.

LAGE, N. Ideologia e Técnica da Notícia. Florianópolis: Insular, 4ª ed. Ver. e atual., 2012. . Estrutura da notícia. Ática, 2006.

A bolha ideológica e o destino do jornalismo. Revista Alceu, n. 3, 2006.

- Teoria e Técnica do Texto Jornalístico. Rio de Janeiro: Elzevier Editora Ltda, 2005.

A reportagem: Teoria e Técnica de Entrevista e Pesquisa Jornalítica. Editora Record, 2003.

. Controle de Opinião Pública: um ensaio sobre a verdade conveniente. $1^{\mathrm{a}} \mathrm{ed}$. Petrópolis: Vozes, 1998. . Linguagem jornalística. Editora Ática, 1985.

MEDITSCH, E.; DE LA BARRERA AYRES, M.; BETTI, J.C.G. Dez anos do Posjor UFSC: relato do percurso e perfil da produção. In: $15^{\circ}$ Encontro Nacional de Pesquisadores em Jornalismo ECA/USP, São Paulo, 2017.

MELO, José Marques de. Teoria do Jornalismo: identidades brasileiras. São Paulo: Paulus, 2006.

SCHUDSON, Michael. Descobrindo a notícia: uma história social dos jornais nos Estados Unidos. Petrópolis: Vozes, 2010.

SOUSA, J.P. Pesquisa e reflexão sobre jornalismo até 1950: a institucionalização do jornalismo como campo de conhecimento e campo científico, 2013. Disponível em: http://www.bocc.ubi.pt/pag/sousa-jorge-pedro-pesquisa-e-reflexao-sobre-jornalismo1950.pdf. Acesso em janeiro de 2018.

Recebido em: $11 / 06 / 2018$

Publicado em: 21/12/2018 